\title{
Short-Term Microbiota Manipulation and Forearm Substrate Metabolism in Obese Men: A Randomized, Double- Blind, Placebo-Controlled Trial
}

\author{
Dorien Reijnders ${ }^{a}, b \quad$ Gijs H. Goossens ${ }^{a}, b$ Gerben D.A. Hermes ${ }^{b, c}$ \\ Hauke Smidt ${ }^{\mathrm{b}, \mathrm{c}}$ Erwin G. Zoetendal ${ }^{\mathrm{b}, \mathrm{c}}$ Ellen E. Blaak ${ }^{\mathrm{a}, \mathrm{b}}$ \\ a Department of Human Biology, NUTRIM School of Nutrition and Translational Research \\ in Metabolism, Maastricht University Medical Center+, Maastricht, The Netherlands. \\ ${ }^{b}$ Top Institute Food and Nutrition, Wageningen, The Netherlands. 'Laboratory of \\ Microbiology, Wageningen University, Wageningen, The Netherlands
}

\section{Keywords}

Microbiota $\cdot$ Skeletal muscle $\cdot$ Obesity $\cdot$ Insulin resistance $\cdot$ Antibiotics

\begin{abstract}
Objective: To investigate the impact of gut microbiota manipulation on fasting and postprandial skeletal muscle metabolism in humans. Methods: 40 obese, insulin-resistant males were randomized to amoxicillin (broad-spectrum antibiotic), vancomycin (narrow-spectrum antibiotic), or placebo (7 days, 1,500 mg/day). Before and after treatment, forearm blood flow and metabolite fluxes across forearm muscle were measured under fasting and postprandial (highfat mixed-meal) conditions. Results: Vancomycin decreased bacterial diversity, reduced the abundance of Gram-positive Firmicutes, and increased the abundance of Gram-negative Proteobacteria, whereas amoxicillin did not affect microbial composition. Neither vancomycin nor amoxicillin treatment affected fasting and postprandial plasma glucose, free fatty acid (FFA), triacylglycerol (TAG), glycerol, lactate, and insulin concentrations or forearm blood flow. Fasting and postprandial net forearm muscle glucose uptake and the release of lactate were not significantly altered by antibiotic treatment as compared to placebo. Finally, antibiotic treatment did not change fasting and postprandial glycerol, FFA, and TAG fluxes across forearm muscle. Conclusion: The present study demonstrates that short-term antibiotic treatment has no effects on fasting and postprandial forearm substrate metabolism and blood flow in obese men with impaired glucose metabolism. These data suggest that short-term strategies targeting the gut microbiota to improve metabolic health may not be effective in obese humans.




\section{Introduction}

The skeletal muscle accounts for approximately $80 \%$ of insulin-stimulated glucose disposal and, therefore, plays a key role in development and progression of insulin resistance and type 2 diabetes mellitus [1]. In the obese state, a reduced adipose tissue lipid buffering capacity increases lipid supply to other tissues such as the skeletal muscle [2]. In addition, impairments in postprandial fatty acid uptake, storage, and oxidation may contribute to intramuscular accumulation of lipid intermediates, which has been associated with insulin resistance $[3,4]$.

Results from several studies suggest that the gut microbiota has potential to impact the physiology of the host and may thereby contribute to insulin resistance [5-10]. For example, skeletal muscle in germ-free mice was characterized by elevated levels of phosphorylated 5 -AMP-activated protein kinase (AMPK) and its downstream targets involved in fatty acid oxidation (i.e. acetyl CoA carboxylase) [5]. Upon transplantation of obese porcine microbiota into germ-free mice, muscle fiber size decreased, and lipogenesis in the mouse skeletal muscle was enhanced [11]. Additionally, the gut hormone glucagon-like peptide (GLP-1) has been found to increase microvascular recruitment and basal glucose uptake in the muscle via a nitric oxide-dependent mechanism [8]. Moreover, short-chain fatty acids (SCFA) that are produced by the gut may have direct effects on peripheral substrate metabolism by binding to their receptors (FFA2 and 3) that are expressed in skeletal muscle [12,13] or indirect effects via FFA2 binding in adipose tissue, thereby suppressing insulin signaling in adipocytes and increasing the lipid supply to skeletal muscle [14-16].

Taken together, these studies suggest that the gut microbiota-skeletal muscle cross-talk might be involved in substrate metabolism and insulin sensitivity $[9,10]$. To our knowledge, only one human study has explored the effects of gut microbiota modifications on skeletal muscle, showing that a prebiotic formulation improved handgrip strength and muscle exhaustion in an older population [17]. The effect on skeletal muscle substrate metabolism and insulin sensitivity under physiological conditions in humans is not known. We hypothesized that changes in the gut microbiota composition alter skeletal muscle metabolism in humans.

We have recently shown that 7-day treatment with the narrow-spectrum antibiotic vancomycin (VANCO) reduced the abundance of Gram-positive Firmicutes that are, amongst others, involved in SCFA metabolism, and increased the abundance of Gram-negative Proteobacteria [18]. In addition, VANCO significantly altered plasma SCFA concentrations and the bile acid (BA) profile [18]. Here, we investigated whether these VANCO-induced effects translate into changes in skeletal muscle blood flow and metabolite fluxes across forearm muscle in obese men with impaired glucose metabolism.

\section{Material and Methods}

\section{Experimental Procedures}

The present study investigated the effects of antibiotic treatment on skeletal muscle substrate metabolism and postprandial insulin sensitivity in 40 obese males with impaired fasting glucose (IFG) and/or impaired glucose tolerance (IGT) [18]. In this randomized, double-blind study with a 3-armed parallel design, participants received either $500 \mathrm{mg}$ /day amoxicillin (AMOX, broad-spectrum), vancomycin (VANCO, narrowspectrum) or placebo for 7 consecutive days. This study was performed in a subgroup of a larger clinical trial, in which we investigated the impact of antibiotic treatment on microbiota composition and tissue-specific insulin sensitivity [18]. The inclusion and exclusion criteria have been reported in detail previously [18]. This study was approved by the local Medical Ethical Committee, and all participants gave written informed consent. All procedures were according to the declaration of Helsinki (revised version, October 2008). 
Table 1. Subject characteristics ${ }^{\mathrm{a}}$

\begin{tabular}{llll}
\hline & PLA (N =13) & AMOX (N = 12) & VANCO (N = 13) \\
\hline Ag, years & $62.6 \pm 1.3$ & $56.3 \pm 2.0$ & $60.0 \pm 1.9$ \\
Body weight, kg & $92.0 \pm 2.4$ & $96.7 \pm 2.9$ & $96.5 \pm 2.5$ \\
BMI, kg/m² & $30.0 \pm 0.6$ & $31.3 \pm 1.1$ & $31.2 \pm 0.8$ \\
Waist/hip ratio & $1.05 \pm 0.01$ & $1.04 \pm 0.02$ & $1.07 \pm 0.02$ \\
Waist circumference, cm & $108.3 \pm 2.1$ & $107.7 \pm 3.4$ & $111.5 \pm 3.0$ \\
Fasting glucose, mmol/l & $6.3 \pm 0.1$ & $6.5 \pm 0.2$ & $6.3 \pm 0.2$ \\
Fasting insulin, mU/l & $11.5 \pm 1.3$ & $12.6 \pm 1.3$ & $14.3 \pm 1.8$ \\
HOMA-IR & $3.3 \pm 0.3$ & $3.1 \pm 0.4$ & $3.9 \pm 0.3$ \\
\hline
\end{tabular}

${ }^{\text {aData }}$ are expressed as mean \pm SEM. No significant differences were found between groups (Student's t-test, $\mathrm{p}>0.05$ ).

\section{Study Procedures}

Before and after the intervention, forearm muscle metabolism and blood flow were studied in the fasting state and for $4 \mathrm{~h}$ after consumption of a high-fat mixed meal (2.6 MJ, consisting of 61 energy\% (E\%) fat, $33 \mathrm{E} \%$ carbohydrate, $6 \mathrm{E} \%$ protein). To this end, catheters were inserted into the superficial dorsal hand vein, which was heated in a hot box $\left(55^{\circ} \mathrm{C}\right)$ to allow arterialized venous blood sampling, and in a deep antecubital vein of the contralateral forearm to sample venous blood. Blood samples were taken simultaneously from these catheters to determine arterio-venous concentration differences of glucose, insulin, lactate, free fatty acids (FFA) and triacylglycerol (TAG), using previously described assays [18]. Forearm blood flow (FBF) was determined at using venous occlusion plethysmography to calculate substrate fluxes across forearm muscle [19]. Using FBF, hematocrit and arterialized and deep-venous plasma concentrations, we calculated the net forearm muscle uptake or release of metabolites. A positive flux indicates net uptake across forearm muscle, whereas a negative flux indicates net release into the circulation $[19,20]$.

For microbiota profiling, DNA was isolated from fecal samples, and subsequently used for phylogenetic profiling using the HIT-Chip phylogenetic microarray [21] as described before [18].

\section{Statistical Analysis}

To be able to detect a differential skeletal muscle lipid handling, $\mathrm{n}=12$ per intervention group has shown to have sufficient power in previous studies [22]. To account for possible drop-outs and block randomization, we decided to include the first 40 participants of the clinical trial for this sub-study in order to reach at least $\mathrm{n}=12$ per group. Repeated-measures ANOVA (SPSS 20.0 for Macintosh (IBM, Armonk, NY, USA)) was used to determine the time $\times$ treatment interaction between groups followed by post-hoc Student's t-test for subgroup analysis. Data are expressed as mean \pm standard error of the mean. $p<0.05$ was considered to be statistically significant.

For HIT-Chip analysis, log10-transformed signals were used as a proxy for bacterial logarithmic abundance. To determine which bacterial groups were significantly different in relative abundance before and after treatment within each group, a paired Wilcoxon test was used. False discovery rate (FDR) was controlled by applying Benjamini-Hochberg correction for multiple testing. Diversity of the microbiota was quantified based on non-logarithmized HIT-Chip oligo-level signals by inverse Simpson's index using the Vegan package [23]. A significance level of FDR $<0.05$ was considered significant. Statistical analyses were performed using SPSS 20.0 for Macintosh and R 3.3.2.

\section{Results}

No serious adverse events of the antibiotic treatment were reported. At baseline, body weight, BMI, and body fat distribution did not differ between groups (table 1). Furthermore, baseline fasting plasma glucose, insulin, lactate, glycerol, TAG, and FFA concentrations were comparable between groups (table 1, fig. 1). 
Reijnders et al.: Short-Term Microbiota Manipulation and Forearm Substrate

Metabolism in Obese Men: A Randomized, Double-Blind, Placebo-Controlled Trial

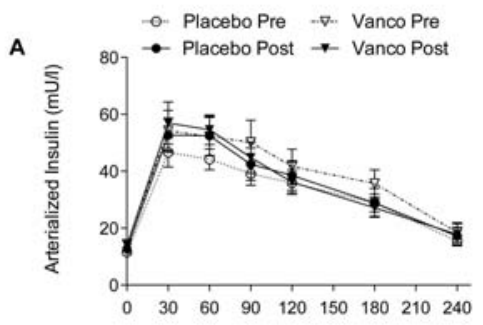

B
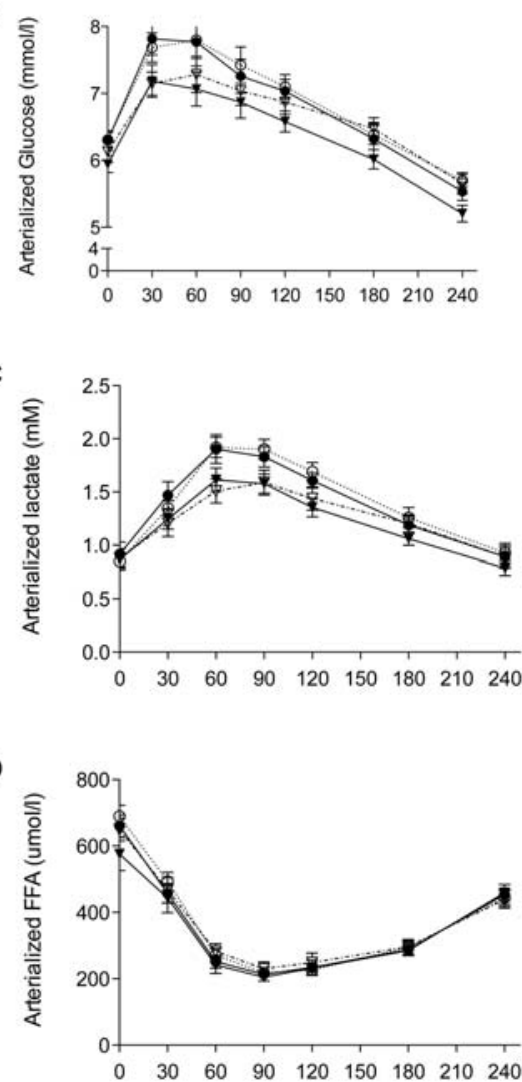

E

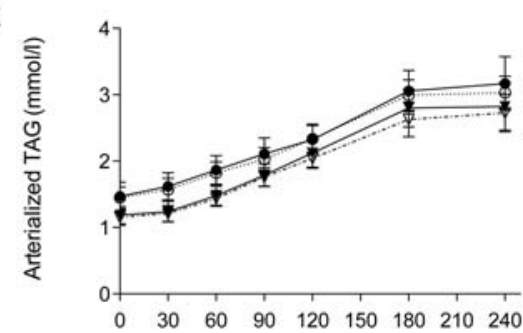

F
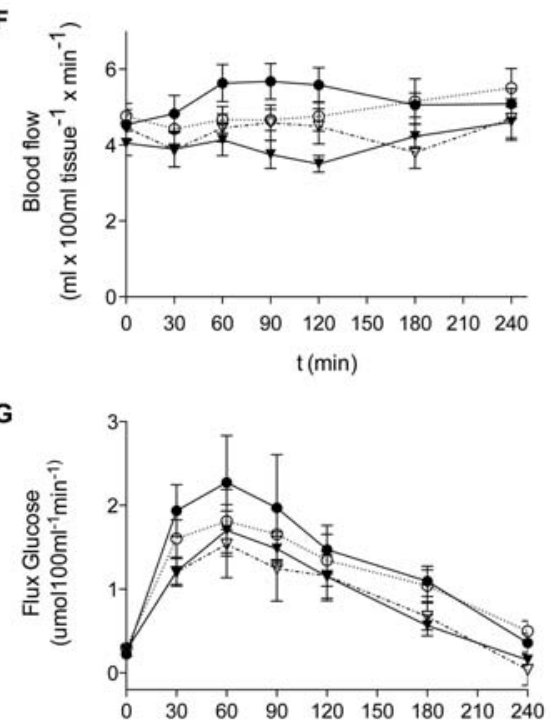

H
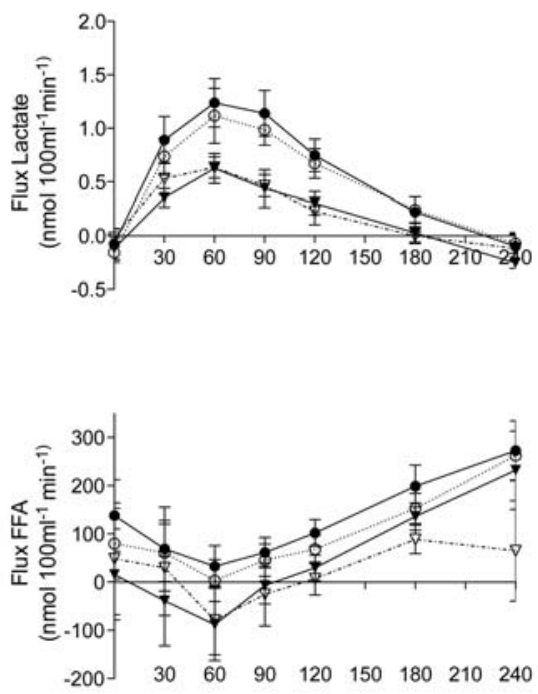

J

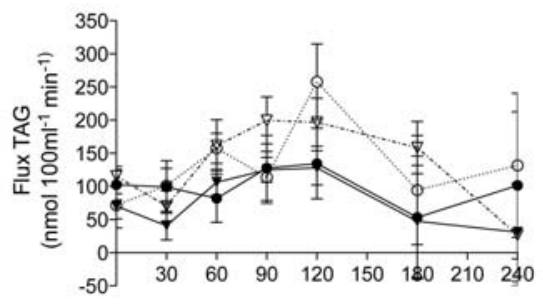

Fig. 1. Effect of 7 days placebo (PLA) or VANCO treatment on plasma concentrations and fluxes of glucose, lactate, FFA, TAG and insulin across forearm muscle. Fasting $(t=0)$ and postprandial concentrations of $(\mathbf{A})$ arterialized insulin, (B) glucose, (C) lactate, (D) free fatty acid (FFA) and (E) triacylglycerol (TAG) concentrations were not affected by VANCO as assessed by repeated measures ANOVA. VANCO did not affect forearm blood flow (F) and net fluxes of (G) glucose, (H) lactate, (I) FFA, and (J) TAG across forearm muscle are shown. A positive flux indicates net uptake across the forearm muscle whereas a negative flux indicates net release. Values are given as mean \pm SEM $(n=37)$. 
Seven-day treatment with the narrow-spectrum antibiotic VANCO decreased the gut bacterial diversity and reduced the abundance of Gram-positive Firmicutes (supplemental fig. 1 and 2, available at http://content.karger.com/ProdukteDB/produkte.asp?doi=492114), which is similar to what we have shown before [18]. VANCO treatment did not significantly affect fasting and postprandial (iAUC/min) circulating metabolite and insulin concentrations as compared to placebo (all $\mathrm{p}>0.05$ ).

Baseline fasting FBF was comparable between groups. Moreover, at baseline, postprandial FBF did not significantly increase after meal intake and was comparable between groups. VANCO treatment had no significant effect on baseline and postprandial FBF as

Table 2. Fasting and postprandial blood flow and lipid metabolism across the forearm muscle ${ }^{a}$

\begin{tabular}{|c|c|c|c|c|c|c|}
\hline & & & $\operatorname{PLA}(n=13)$ & $\operatorname{AMOX}(\mathrm{n}=12)$ & $\operatorname{VANCO}(\mathrm{n}=13)$ & $\mathrm{p}$ value \\
\hline \multicolumn{7}{|l|}{ Forearm blood flow, $\mathrm{ml} \times 100 \mathrm{ml} \times \min ^{-1}$} \\
\hline & $\mathrm{F}$ & pre & $4.75 \pm 0.38$ & $4.28 \pm 0.52$ & $4.26 \pm 0.43$ & 0.399 \\
\hline & & post & $4.56 \pm 0.42$ & $4.31 \pm 0.45$ & $3.83 \pm 0.36$ & \\
\hline & $\mathrm{P}$ & pre & $4.93 \pm 0.41$ & $4.71 \pm 0.32$ & $4.24 \pm 0.44$ & 0.444 \\
\hline & & post & $5.31 \pm 0.32$ & $4.80 \pm 0.39$ & $3.99 \pm 0.24$ & \\
\hline \multicolumn{7}{|l|}{ Net flux across forearm muscle } \\
\hline \multirow[t]{4}{*}{ Glucose, $\mu \mathrm{mol} \times 100 \mathrm{ml} \times \mathrm{min}^{-1}$} & $\mathrm{~F}$ & pre & $0.30 \pm 0.06$ & $0.26 \pm 0.04$ & $0.28 \pm 0.08$ & 0.759 \\
\hline & & post & $0.22 \pm 0.05$ & $0.26 \pm 0.05$ & $0.24 \pm 0.04$ & \\
\hline & $\mathrm{P}$ & pre & $0.93 \pm 0.17$ & $0.70 \pm 0.15$ & $0.78 \pm 0.22$ & 0.689 \\
\hline & & post & $1.16 \pm 0.26$ & $0.88 \pm 0.20$ & $0.72 \pm 0.11$ & \\
\hline \multirow[t]{4}{*}{ Lactate, $\mu \mathrm{mol} \times 100 \mathrm{ml} \times \min ^{-1}$} & $\mathrm{~F}$ & pre & $-0.16 \pm 0.09$ & $-0.21 \pm 0.06$ & $-0.05 \pm 0.08$ & 0.761 \\
\hline & & post & $-0.08 \pm 0.14$ & $-0.21 \pm 0.07$ & $-0.05 \pm 0.09$ & \\
\hline & $\mathrm{P}$ & pre & $0.68 \pm 0.07$ & $0.48 \pm 0.08$ & $0.28 \pm 0.06$ & 0.146 \\
\hline & & post & $0.66 \pm 0.08$ & $0.38 \pm 0.08$ & $0.39 \pm 0.08$ & \\
\hline \multirow[t]{4}{*}{ Free glycerol, $\mathrm{nmol} \times 100 \mathrm{ml} \times \min ^{-1}$} & $\mathrm{~F}$ & pre & $-33.54 \pm 12.78$ & $-11.32 \pm 12.65$ & $-54.98 \pm 23.05$ & 0.232 \\
\hline & & post & $-23.24 \pm 12.44$ & $-16.72 \pm 6.94$ & $-42.17 \pm 15.20$ & \\
\hline & $\mathrm{P}$ & pre & $26.36 \pm 7.59$ & $6.89 \pm 9.24$ & $26.61 \pm 13.91$ & 0.480 \\
\hline & & post & $11.50 \pm 8.26$ & $10.20 \pm 5.64$ & $24.82 \pm 8.08$ & \\
\hline \multirow[t]{4}{*}{ FFA, $\mathrm{nmol} \times 100 \mathrm{ml} \times \mathrm{min}^{-1}$} & $\mathrm{~F}$ & pre & $79.62 \pm 73.53$ & $132.78 \pm 58.48$ & $47.55 \pm 128.34$ & 0.341 \\
\hline & & post & $138.02 \pm 74.09$ & $82.37 \pm 45.44$ & $-12.66 \pm 99.52$ & \\
\hline & $\mathrm{P}$ & pre & $22.88 \pm 41.28$ & $-42.76 \pm 39.70$ & $-17.59 \pm 78.32$ & 0.220 \\
\hline & & post & $-6.09 \pm 45.41$ & $6.94 \pm 32.96$ & $55.89 \pm 57.09$ & \\
\hline \multirow[t]{4}{*}{$\mathrm{TAG}, \mathrm{nmol} \times 100 \mathrm{ml} \times \mathrm{min}^{-1}$} & $\mathrm{~F}$ & pre & $71.56 \pm 34.22$ & $-15.55 \pm 58.39$ & $113.88 \pm 15.75$ & 0.100 \\
\hline & & post & $102.56 \pm 22.88$ & $78.15 \pm 28.78$ & $71.29 \pm 21.03$ & \\
\hline & $\mathrm{P}$ & pre & $67.90 \pm 48.47$ & $117.22 \pm 66.78$ & $20.99 \pm 16.47$ & 0.838 \\
\hline & & post & $-6.37 \pm 37.43$ & $61.06 \pm 31.12$ & $0.34 \pm 14.94$ & \\
\hline
\end{tabular}

$\mathrm{PLA}=$ Placebo; $\mathrm{AMOX}=$ amoxicillin; VANCO = vancomycin; $\mathrm{F}=$ fasting; $\mathrm{P}=$ postprandial $(0-4 \mathrm{~h}) ; \mathrm{TAG}=$ triacyglycerol; FFA $=$ free fatty acid.

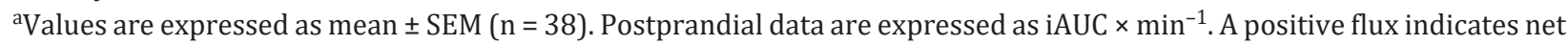
uptake across forearm muscle whereas a negative flux indicates net release.

Fig. 2. Effect of 7 days placebo (PLA) or AMOX treatment on plasma concentrations and fluxes of glucose, lactate, FFA, TAG and insulin across forearm muscle. Fasting $(\mathrm{t}=0)$ and postprandial concentrations of $(\mathbf{A})$ arterialized insulin, (B) glucose, (C) lactate, (D) free fatty acid (FFA) and (E) triacylglycerol (TAG) concentrations were not affected by AMOX as assessed by repeated measures ANOVA. AMOX did not affect forearm blood flow (F) and net fluxes of (G) glucose, (H) lactate, (I) FFA, and (J) TAG across forearm muscle are shown. A positive flux indicates net uptake across the forearm muscle; a negative flux indicates net release. Values are given as mean \pm SEM $(n=37)$.

(For figure see next page.) 
Reijnders et al.: Short-Term Microbiota Manipulation and Forearm Substrate

Metabolism in Obese Men: A Randomized, Double-Blind, Placebo-Controlled Trial

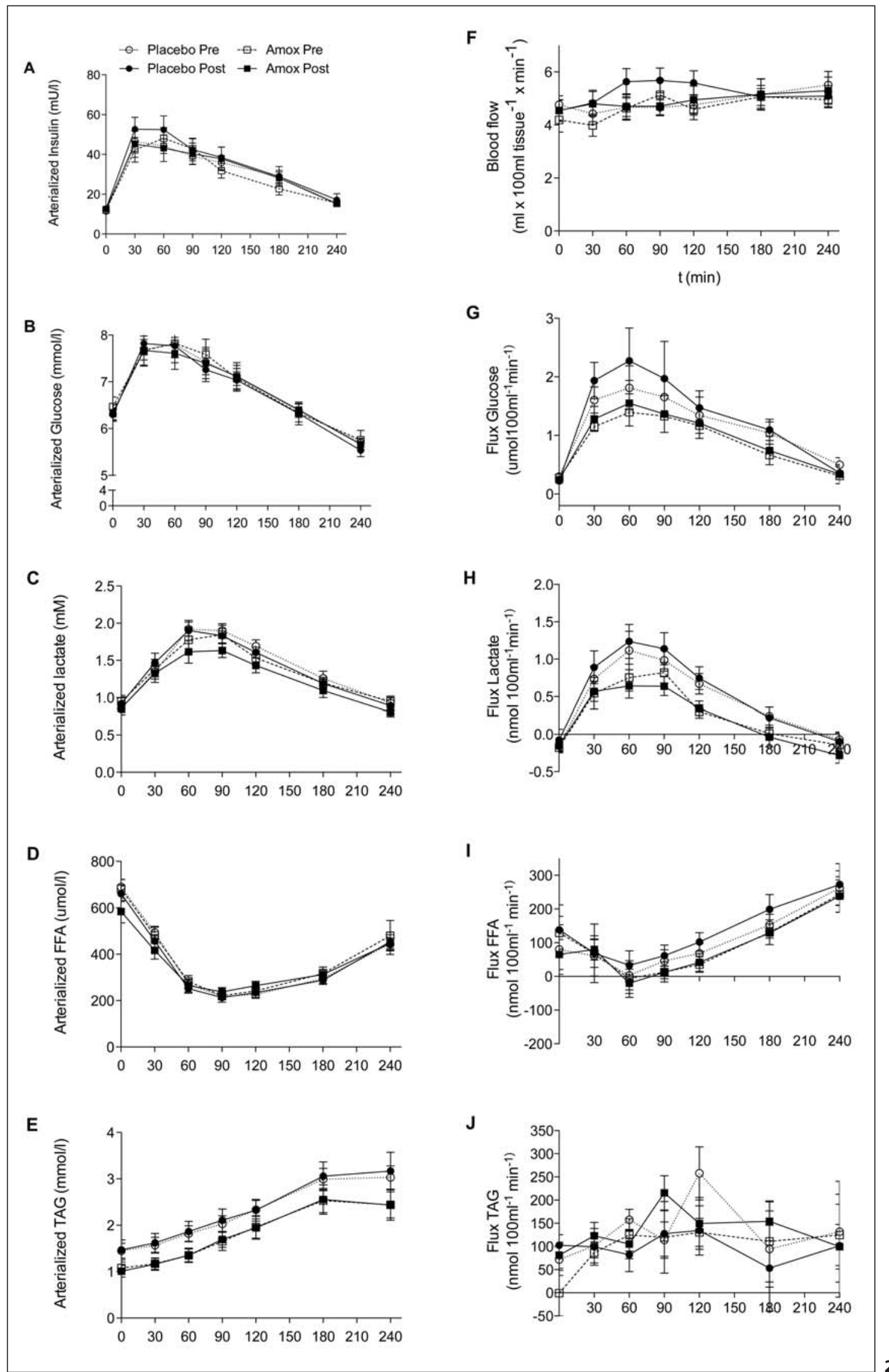


compared to placebo (fig. 1). Furthermore, we found no significant effects of VANCO on fasting and postprandial net forearm muscle glucose uptake, the release of lactate across forearm muscle, fasting and postprandial glycerol as well as FFA and TAG fluxes across forearm muscle as compared to placebo (table 2). In line with the lack of effect on the gut microbial profile (supplemental fig. 1 and 2, available at http://content.karger.com/ProdukteDB/produkte. asp?doi=492114), AMOX treatment had no significant effects on plasma metabolite concentrations, FBF and forearm substrate fluxes under fasting and postprandial conditions (table 2, fig. 2).

\section{Discussion}

The present study demonstrated that antibiotic treatment for 7 days using VANCO or AMOX had no significant effects on fasting and postprandial forearm muscle substrate metabolism and postprandial insulin sensitivity in obese men with impaired glucose homeostasis. We [18] and others [24] have previously demonstrated that 7-day VANCO treatment affected microbial diversity and composition. These results were confirmed in the present study including obese men with impaired glucose metabolism. Briefly, the abundance of butyrateproducing species and species involved in BA dehydroxylation decreased following VANCO, whilst there was a compensatory increase of Gram-negative Proteobacteria and VANCOresistant bacilli. This was accompanied by a reduced conversion of primary to secondary BA and a lower production of SCFA in the gut [18]. Alterations in gut hormones and microbial products such as SCFA $[8,25]$, have been suggested to underlie changes in skeletal muscle fat oxidation and substrate metabolism following gut microbiota manipulation. More specific, it has been suggested that the stimulation of fat oxidation in skeletal muscle might be under influence of gut-derived hormones and substrates such as SCFA and BA through metabolic pathways involving the phosphorylation of AMPK [5], which in turn regulates skeletal muscle glucose uptake [26]. However, the present study demonstrated that VANCO-induced changes in plasma SCFA and BA concentrations did not affect forearm muscle metabolism in humans. We found that VANCO treatment did neither influence systemic lipid overflow, i.e. fasting and postprandial TAG and FFA concentrations, nor postprandial glucose and insulin concentrations. Together with an unchanged postprandial forearm muscle glucose flux following VANCO treatment, these findings indicate that postprandial insulin sensitivity was not affected.

In line with unchanged microbial and metabolic profiles following AMOX treatment [18], we found no significant effects of AMOX on forearm substrate metabolism in the present study.

Our data are in contrast to rodent studies showing that the gut microbiota exert effects on substrate and energy metabolism [6,7,27-31]. Although it has previously been suggested that antibiotic treatment may improve metabolic impairments in mice [27-30], a 4-day broad-spectrum antibiotic cocktail did not affect postprandial glucose metabolism in lean, healthy men [32]. Moreover, we have previously shown that whole-body insulin sensitivity, determined by the gold-standard hyperinsulinemic-euglycemic clamp, was not affected by 7-day antibiotic treatment [18]. Noteworthy, in rodent studies, animals were exposed to antibiotics in their drinking water for at least 4 weeks. Similarly, more prolonged treatment (4-6 weeks) with a higher dosage or a combination of antibiotics, increased body weight in endocarditis patients $[33,34]$. Although these studies may indicate that long-term dysbalance in microbiota composition has more pronounced effects as compared to short-term manipulation, no significant changes in glucose and insulin concentrations as well as whole-body insulin sensitivity were found 8 weeks after cessation of VANCO treatment, despite a still considerably altered microbial composition as compared to pre-treatment [18]. 
In conclusion, the present study demonstrated that, despite marked changes in gut microbiota composition following VANCO treatment, forearm substrate metabolism and postprandial glucose metabolism were not altered by 7-day antibiotic treatment in obese men with impaired glucose metabolism. Our data suggest that strategies targeting the gut microbiota (i.e. specific dietary interventions) may not be effective in improving metabolic health in obese humans. Further research should establish whether more prolonged manipulation of the gut microbiota, in a larger group of subjects, may induce changes in skeletal muscle substrate metabolism and thereby provides opportunities to improve metabolic health.

\section{Author Contributions}

D.R., G.G. and E.B. designed the study and analyzed the data; D.R. contributed to data acquisition and wrote the manuscript; E.B. had the primary responsibility for the final content. All authors revised the content of the manuscript, read, and approved the manuscript for publication.

\section{Trial Registration}

ClinicalTrials.gov: NCT02241421

\section{Acknowledgments}

We thank Hasibe Aydeniz, Jos Stegen, and Wendy Sluijsmans from the Department of Human Biology, Maastricht University Medical Center+, for their excellent analytical support, and all subjects for their participation in the study.

\section{Disclosure Statement}

The research is funded by TI Food and Nutrition, a public-private partnership on pre-competitive research in food and nutrition. The funders had no role in study design, data collection and analysis, decision to publish, or preparation of the manuscript. The authors have declared that no competing interests exist.

\section{References}

1 Thiebaud D, Jacot E, DeFronzo RA, Maeder E, Jequier E, Felber JP: The effect of graded doses of insulin on total glucose uptake, glucose oxidation, and glucose storage in man. Diabetes 1982;31:957-963.

-2 Stinkens R, Goossens GH, Jocken JW, Blaak EE: Targeting fatty acid metabolism to improve glucose metabolism. Obes Rev 2015;16:715-757.

-3 Farese RV Jr, Yost TJ, Eckel RH: Tissue-specific regulation of lipoprotein lipase activity by insulin/glucose in normal-weight humans. Metabolism 1991;40:214-216.

4 Ritter O, Jelenik T, Roden M: Lipid-mediated muscle insulin resistance: different fat, different pathways? J Mol Med 2015;93:831-843.

5 Backhed F, Manchester JK, Semenkovich CF,Gordon JI: Mechanisms underlying the resistance to diet-induced obesity in germ-free mice. ProcNatl Acad Sci U S A 2007;104:979-984.

6 Bech-Nielsen GV, Hansen CH, Hufeldt MR, Nielsen DS, Aasted B, Vogensen FK, Midtvedt T, Hansen AK: Manipulation of the gut microbiota in C57BL/6 mice changes glucose tolerance without affecting weight development and gut mucosal immunity. Res Vet Sci 2012;92:501-508.

7 Carvalho BM, Guadagnini D, Tsukumo DM, Schenka AA, Latuf-Filho P, Vassallo J, Dias JC, Kubota LT, Carvalheira JB, Saad MJ: Modulation of gut microbiota by antibiotics improves insulin signalling in high-fat fed mice. Diabetologia 2012;55:2823-2834.

-8 Chai W, Dong Z, Wang N, Wang W, Tao L, Cao W, Liu Z: Glucagon-like peptide 1 recruits microvasculature and increases glucose use in muscle via a nitric oxide-dependent mechanism. Diabetes 2012;61:888-896.

-9 Cox LM, Blaser MJ: Pathways in microbe-induced obesity. Cell Metab 2013;17:883-894. 
Reijnders et al.: Short-Term Microbiota Manipulation and Forearm Substrate

Metabolism in Obese Men: A Randomized, Double-Blind, Placebo-Controlled Trial

10 Khan MT, Nieuwdorp M, Backhed F: Microbial modulation of insulin sensitivity. Cell Metab 2014;20:753-760.

-11 Yan H, Diao H, Xiao Y, Li W, Yu B, He J, Yu J, Zheng P, Mao X, Luo Y, Zeng B, Wei H, Chen D: Gut microbiota can transfer fiber characteristics and lipid metabolic profiles of skeletal muscle from pigs to germ-free mice. Sci Rep 2016;6:31786.

12 Cornall LM, Mathai ML, Hryciw DH, McAinch AJ: Diet-induced obesity up-regulates the abundance of GPR43 and GPR120 in a tissue specific manner. Cell Physiol Biochem 2011;28:949-958.

13 Bonini JA, Anderson SM, Steiner DF: Molecular cloning and tissue expression of a novel orphan G proteincoupled receptor from rat lung. Biochem Biophys Res Commun 1997;234:190-193.

14 Ge H, Li X, Weiszmann J, Wang P, Baribault H, Chen JL, Tian H, Li Y: Activation of G protein-coupled receptor 43 in adipocytes leads to inhibition of lipolysis and suppression of plasma free fatty acids. Endocrinology 2008;149:4519-4526.

15 Hong YH, Nishimura Y, Hishikawa D, Tsuzuki H, Miyahara H, Gotoh C, Choi KC, Feng DD, Chen C, Lee HG, Katoh K, Roh SG, Sasaki S: Acetate and propionate short chain fatty acids stimulate adipogenesis via GPCR43. Endocrinology 2005;146:5092-5099.

16 Kimura I, Ozawa K, Inoue D, Imamura T, Kimura K, Maeda T, Terasawa K, Kashihara D, Hirano K, Tani T, Takahashi T, Miyauchi S, Shioi G, Inoue H, Tsujimoto G: The gut microbiota suppresses insulin-mediated fat accumulation via the short-chain fatty acid receptor GPR43. Nat Commun 2013;4:1829.

-17 Buigues C, Fernandez-Garrido J, Pruimboom L, Hoogland AJ, Navarro-Martinez R, Martinez-Martinez M, Verdejo Y, Mascaros MC, Peris C, Cauli O: Effect of a prebiotic formulation on frailty syndrome: a randomized, double-blind clinical trial. Int J Mol Sci 2016;17.

18 Reijnders D, Goossens GH, Hermes GD, Neis EP, van der Beek CM, Most J, Holst JJ, Lenaerts K, Kootte RS, Nieuwdorp M, Groen AK, Olde Damink SW, Boekschoten MV, Smidt H, Zoetendal EG, Dejong CH, Blaak EE: Effects of gut microbiota manipulation by antibiotics on host metabolism in obese humans: a randomized doubleblind placebo-controlled trial. Cell Metab 2016;24:63-74.

19 Blaak EE, Wagenmakers AJ, Glatz JF, Wolffenbuttel BH, Kemerink GJ, Langenberg CJ, Heidendal GA, Saris WH: Plasma FFA utilization and fatty acid-binding protein content are diminished in type 2 diabetic muscle. Am J Physiol Endocrinol Metab 2000;279:E146-154.

-20 Blaak EE, van Baak MA, Kemerink GJ, Pakbiers MT, Heidendal GA, Saris WH: Total forearm blood flow as an indicator of skeletal muscle blood flow: effect of subcutaneous adipose tissue blood flow. Clin Sci 1994;87: 559-566.

-21 Rajilic-Stojanovic M, Heilig HG, Molenaar D, Kajander K, Surakka A, Smidt H, de Vos WM:Development and application of the human intestinal tract chip, a phylogenetic microarray: analysis of universally conserved phylotypes in the abundant microbiota of young and elderly adults. Environ Microbiol 2009;11:1736-1751.

-22 van Hees AM, Jans A, Hul GB, Roche HM, Saris WH, Blaak EE: Skeletal muscle fatty acid handling in insulin resistant men. Obesity (Silver Spring) 2011;19:1350-1359.

23 Oksanen JFGB KR, Legendre P, Minchin PR, O'Hara RB, Simpson GL, et al: Package 'vegan' version 2.0-2. 2011.

-24 Vrieze A, Out C, Fuentes S, Jonker L, Reuling I, Kootte RS, van Nood E, Holleman F, Knaapen M, Romijn JA, Soeters MR, Blaak EE, Dallinga-Thie GM, Reijnders D, Ackermans MT, Serlie MJ, Knop FK, Holst JJ, van der Ley C, Kema IP, Zoetendal EG, de Vos WM, Hoekstra JB, Stroes ES, Groen AK, Nieuwdorp M: Impact of oral vancomycin on gut microbiota, bile acid metabolism, and insulin sensitivity. J Hepatol 2014;60:824-831.

-25 Cherbut C, Ferrier L, Roze C, Anini Y, Blottiere H, Lecannu G, Galmiche JP: Short-chain fatty acids modify colonic motility through nerves and polypeptide YY release in the rat. Am J Physiol 1998;275:G1415-1422.

-26 McGee SL, Hargreaves M: AMPK-mediated regulation of transcription in skeletal muscle. Clin Sci 2010;118: 507-518.

27 Hwang I, Park YJ, Kim YR, Kim YN, Ka S, Lee HY, Seong JK, Seok YJ, Kim JB: Alteration of gut microbiota by vancomycin and bacitracin improves insulin resistance via glucagon-like peptide 1 in diet-induced obesity. FASEB J 2015;29:2397-2411.

-28 Murphy EF, Cotter PD, Hogan A, O’Sullivan O, Joyce A, Fouhy F, Clarke SF, Marques TM, O’Toole PW, Stanton C, Quigley EM, Daly C, Ross PR, O’Doherty RM, Shanahan F: Divergent metabolic outcomes arising from targeted manipulation of the gut microbiota in diet-induced obesity. Gut 2013;62:220-226.

-29 Chou CJ, Membrez M, Blancher F: Gut decontamination with norfloxacin and ampicillin enhances insulin sensitivity in mice. Nestle Nutr Workshop Ser Pediatr Program. 2008;62:127-137; discussion 37-40.

-30 Membrez M, Blancher F, Jaquet M, Bibiloni R, Cani PD, Burcelin RG, Corthesy I, Mace K, Chou CJ: Gut microbiota modulation with norfloxacin and ampicillin enhances glucose tolerance in mice. FASEB J 2008;22:2416-2426.

-31 Rune I, Hansen CH, Ellekilde M, Nielsen DS, Skovgaard K, Rolin BC, Lykkesfeldt J, Josefsen K, Tranberg B, Kihl P, Hansen AK: Ampicillin-improved glucose tolerance in diet-induced obese C57BL/6NTac mice is age dependent. J Diabetes Res 2013;2013:319321.

-32 Mikkelsen KH, Frost M, Bahl MI, Licht TR, Jensen US, Rosenberg J, Pedersen O, Hansen T, Rehfeld JF, Holst JJ, Vilsboll T, Knop FK: Effect of antibiotics on gut microbiota, gut hormones and glucose metabolism. PloS One 2015;10:e0142352.

33 Thuny F, Richet H, Casalta JP, Angelakis E, Habib G, Raoult D: Vancomycin treatment of infective endocarditis is linked with recently acquired obesity. PloS One 2010;5:e9074.

-34 Million M, Thuny F, Angelakis E, Casalta JP, Giorgi R, Habib G, Raoult D: Lactobacillus reuteri and Escherichia coli in the human gut microbiota may predict weight gain associated with vancomycin treatment. Nutr Diabetes 2013;3:e87. 